\title{
CANOPY DURATION AND STRUCTURE OF PIGEONPEA INTERCROPPED WITH UPLAND RICE
}

\author{
By A. RAMAKRISHNA, C. K. ONG and S. L. N. REDDY" \\ International Crops Research Institute for the Semi-Arid Tropics (ICRIS.AT). \\ Pantancheru PO. Andhra Pradesh .502.324, India
}

(Accepled 1.5 October 1991)

\begin{abstract}
SLMMIARI
Interactions between upland rice and three phenolugically distinct pigempeat cultivars were examined on a medium deep Vertisol. The productivity of each intercrop compenent and its respective sole crop was determined in terms of a crop performanter rattio (C:PR). The extraearly pigeonpea cultivar recorded the langest partial (:PR of grain fillowed by early and medium genotypes. Spresding genotspes had a larger partial (:PR than semi-compant genotypes. However, the (:PR of intercropped rice was less (0.65-0.(i9) with sprrating pigeonpeas but exceeded unity with compatet types. The camopy strurture of pigeompera appeared to be more important than diflerences in phenolugy. A large range of light

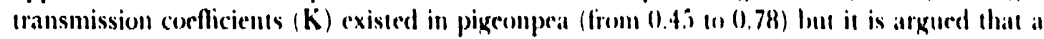
further reduction in $\mathrm{K}$ may not be necessary siner intercropped rice yield was unaffected eve"l with a $K$ of 0.64 . The relative height of intercropped pigerompea and upland rice maly also determine competitive ability since rice is very sensitive to low light and shading. particularly during the reproductive phase.
\end{abstract}

Siembra simultánea de ( Gajanus cajan (L) .Millsp.y arros de lierras allus.

\section{RESUMEN}

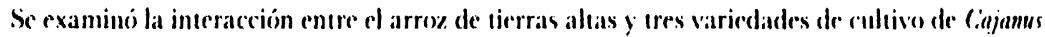
cajan (L) Millsp fenologicamente distintas en Vertisol con profundidad media. Se determino la productividad de cada componente del cultivo simultáneo y de su respectivo cultivo independiente en términos de la relación de rendimiento de cosecha (RRC). La variedad extratemprana de Cajanus cajan registró la mayor RRC: parcial de grano, seguida por el genotipo temprano y por el medio. Los genotipos diseminados presentaron una matyor RRC: parcial pue Ios genutipos semicompactos. Sin embargo, la RRC del arro\% cultivado cn forma simultánea fur menor con los Ciajanus cajan diseminados, pero excedió la unidad con los tipes compactos. Al parecer, la estructura de bóveda del Ciajanus cajan fue maís importante que las diferencias de fenología. En el Ciajanus cajan se dio una extensa gama de corficirntes de transmisión de luz (K) de 0,45 a 0,78 , pero se presume que tal vez no resulte necesaria una mayor reducción de $K$, dado que el rendimiento del arroz sembrado en forma simultánea no se vio afectado, ni siquiera con un $\mathrm{K}$ de 0,64 . La altura relativa de la cosecha simultánea de Cajanus cajan y arroz de tierras altas también puede determinar su habilidad competitiva, dado que el arroz es muy sensible a la baja cantidad de luz y la sombra, en particular, durante la fase reproductiva.

\section{INTRODUCTION}

Pigeonpea (Cajanus cajan (L.) Millsp) is an important tropical grain legume commonly intercropped with cereals such as rice in the uplands (Parida et al., 
1988) or sorghum in the Deccan plateau of semi-arid India (Rao and Willey, 1983). Research on sorghum/pigeonpea is more advanced than that on upland rice/pigeonpea, and has shown that the greater productivity of the sorghum/ pigeonpea system is a result of better utilization of total intercepted radiation (Natarajan and Willey, 1979). In this system sorghum is generally more competitive than pigeonpea, but distinct differences in the maturity periods of the component crops generally allow better use of resources over time (Freyman and Venkateshwarlu, 1977). However, factors other than temporal differences, such as canopy differences or possible differences in rooting pattern, are also important and may result in better 'spatial' use of resources (Rao and Willey, 1980). In sharp contrast, the yield of upland rice is unstable when intercropped with pigeonpea, since upland rice suffers an appreciable degree of competition. Presumably differences in growth habit contribute to differences in competitive ability. In addition, both upland rice and pigeonpea are sensitive to the moisture regime, rice to drought and pigeonpea to excess soil moisture.

Despite these constraints, intercropping upland rice with pigeonpea provides a yicld advantage of $301070 \%$ (Parida et al., 1988; Jena and Misra, 1988). In most cases, this yicld advantage is achieved despite a substantial reduction in the yield of intercropped rice. However, studies by Ramakrishna and Ong (1991) indicate that an intercropping advantage of $41-74 \%$ can be achieved with only a small reduction in rice yicld. They showed that the canopy cover of the determinate pigeonpea cv. IC:PL 87 is limited even when low rainfall restricts canopy development in the rice. On the other hand, the canopy of pigeonpea cr. HY $3 \mathrm{C}$ : expands rapidly under the same conditions, shading and greatly reducing the growth of upland rice. However, because the two pigeonpea genotypes used in their study also differed in the duration of maturity, it was not possibte to distinguish between the effects of duration (phenology) and morphology.

The objectives of selection for intercropping can be very simply stated as the selection of genotypes that minimize intercrop competition and maximize complementary effects. Ideally this should involve the identification of the plant characteristics associated with good intercropping performance. This paper briefly describes how the duration and canopy structure of pigeonpea influence the yield of upland rice in a pigeonpea/upland rice intercropping system.

\section{MATERIALS AND METHODS}

\section{Site}

The experiment was conducted during the rainy season of 1990 at the International Crops Research Institute for the Semi-Arid Tropics (ICRISAT), Patancheru, India $\left(17^{\circ} 38^{\prime} \mathrm{N}, 78^{\circ} 21^{\prime} \mathrm{E}\right)$. The site was a medium deep Vertisol (black soil) with an available water-holding capacity of approximately $200 \mathrm{~mm}$ in the top $150 \mathrm{~cm}$ (Singh and Virmani, 1990). The long term average rainfall at the site during the rainy season (June-October) is $610 \mathrm{~mm}$. During 1990, the rain received was $500 \mathrm{~mm}$ over the period of rice growth (June-September), $163 \mathrm{~mm}$ 
Table 1. Plant population (plants $m{ }^{-}$) and hariest dates of treatments

\begin{tabular}{|c|c|c|c|c|c|}
\hline \multirow{2}{*}{$\begin{array}{c}, \\
\text { Cirop }\end{array}$} & \multicolumn{2}{|c|}{ Sole } & \multicolumn{2}{|c|}{ Intercrop } & \multirow{2}{*}{$\begin{array}{l}\text { Date of } \\
\text { harvest }\end{array}$} \\
\hline & Initail & Final & Initial & Final & \\
\hline \multicolumn{6}{|l|}{ Rice } \\
\hline IET 7613 & 100 & $1(x)$ & 83.2 & 83.2 & 2.5 September \\
\hline \multicolumn{6}{|l|}{ Pigeonpea } \\
\hline \multicolumn{6}{|c|}{ Medium duration crs } \\
\hline IC.PI. 211 & 8.3 & 3.1 & +.2 & 21 & $2+1$ Decomber \\
\hline IC:PI, 87.4 & 8.3 & 6.6 & +.2 & 3.6 & $2+1$ Drcember \\
\hline \multicolumn{6}{|l|}{ Earl! crs } \\
\hline IC:PI. 87 & 33.3 & 27.4 & 8.3 & 6.8 & 2:3 Norember \\
\hline$I(: P L+86.5$ & 33.3 & 30.0 & 8.3 & 7.7 & 21 Normber \\
\hline \multicolumn{6}{|l|}{ Fxtra-carly ass } \\
\hline IC:PI. 83015) & 33.3 & 1.67 & 8.3 & 0.4 & 20 Sicptember \\
\hline IC:PI. 84()'23 & 33.3 & 27.1 & 8.3 & $7.1)$ & 26 Sicptember \\
\hline
\end{tabular}

before crop sowing and $189 \mathrm{~mm}$ after the rice harvest. Distribution was not uniform: periods of drought ranged from five to nine days and aloout $4(1) \%$ of the seasonal rain was received in August. Irrigation was provided to simulate the rainfall received in upland rice growing areas.

\section{Treatments and design}

Cultivars of pigeonpea were chosen to provide a range of duration as follows: two medium duration cultivars maturing in 160-180 days, I(:PI. 211 with erect and IC.PL 8744 with spreading branching; two carly cultivars maturing in 13.5150 day's, IC.PL 87 with semi-compact and IC.PI 486.5 with spreading branching; and two extra early cultivars maturing in 90-105 days, IC:PI, 83015 and IC.PI 84023 , both with erect branching. All the pigeonpea cultivars and the rice were grown at their recommended plant populations ('Table 1). In all the intercrops, five rice rows were alternated with one legume row. The experiment consisted of 14 treatments and the design was a randomized block with four replications. The plot size for each treatment was $8.4 \times 7 \mathrm{~m}$ and each plot consisted of seven sets of five rice rows and one legume row, of which the middle four sets were harvested. Crops were sown on 20 June 1990.

A basal dressing of $100 \mathrm{~kg} \mathrm{ha}^{-1}$ diammonium phosphate $(18 \% \mathrm{~N}, 20 \% \mathrm{P})$ was applied prior to the last cultivation before sowing. The equivalent of $42 \mathrm{~kg} \mathrm{~N} \mathrm{ha}^{-1}$ (taking into account the area occupied by both the crops) was later top-dressed as urea along the sides of the rice rows at the time of tillering and panicle initiation in the rice.

\section{Growth measurements}

Rice and pigeonpea plants were harvested from $1.2 \mathrm{~m}^{2}$ at $20 \mathrm{~d}$ intervals, commencing $20 \mathrm{~d}$ after emergence. Plant material was separated into leaves, stems, pods and panicles. Leaf area was measured using a LI-COR LI 3100 leaf 
area meter, and all material was then dried at $80^{\circ} \mathrm{C}$ to constant weight. Final harvests for recording the grain and total dry matter of straw or stalks were taken from an area of $28.8 \mathrm{~m}^{2}$. Harvest dates are shown in Table 1 .

To assess the advantage of intercropping in terms of the dry weight of harvested material, the yield per unit area of a component of the intercrop (I) was divided by the proportion $(\mathrm{P})$ of that component in the intercrop to give the yield per unit area sown to that component (I/P). This quantity was then expressed as a fraction of the same component in the sole plot (S) to give crop performance ratios (C.PR) of $\mathrm{I}_{r} /\left(\mathrm{P}_{\mathrm{r}} \mathrm{S}_{\mathrm{r}}\right)$ for rice and $\mathrm{I}_{\mathrm{p}} /\left(\mathrm{P}_{\mathrm{p}} \mathrm{S}_{\mathrm{p}}\right)$ for pigeonpea. The corresponding ratio for the whole intercrop, the total crop performance ratio (TC.PR), is given by the equation:

$$
\operatorname{TCPR}=\left(I_{r}+I_{p}\right) /\left(P_{r} S_{r}+P_{p} S_{p}\right) \quad(\text { Harris et al., 1987) }
$$

The 'expected' performance of a component of an intercrop is calculated in this paper as the value per unit area in the sole stand multiplied by the sown proportion of that component in the intercrop. Values of C.PR exceeding unity imply that a component yielded more dry matter per unit sown area in the intercrop treatment than in the sole plot, and thus performed better than 'expected' on the basis of its sole crop yield. Values of TC.PR exceeding unity imply that the intercrop plot yiclded more than a corresponding area of both the component crops grown alone. For our analysis, CPR and TC.PR are more appropriate bases for calculating the biological advantage of an intercrop than the more conventional land equivalent ratio (LER), since in this case the purpose is to compare the 'efficiency' with which sole crops and intercrops use intercepted radiation to produce dry matter. However, land equivalent ratio values are included in the results to allow comparison with the results obtained by other workers.

\section{Light measurements}

Light interception was measured once in 10 days with a 'mouse' radiation integrator $1 \mathrm{~m}$ long and sensitive to total solar radiation (Matthews et al., 1987). Crop rows ran in a north to south direction and light interception was measured across five rows of rice by placing the integrator across the rows. Percentage light interception was calculated from the radiation measured above and below the crop canopy. Absolute incident energy was recorded with a Kipp and Zonen solarimeter at a meteorological station $500 \mathrm{~m}$ from the site.

\section{RESULTS}

\section{Leaf area and dry matter production}

There was a wide range in the rate of canopy development for the different pigeonpea genotypes in sole stands (Fig. 1a). The medium duration types had the slowest rate, mainly because of substantially smaller plant populations ( 3 to 6.6 plants $\mathrm{m}^{-2}$ compared with 16.7 to 30 plants $\mathrm{m}^{-2}$ in the earlier types). ICPL 87 


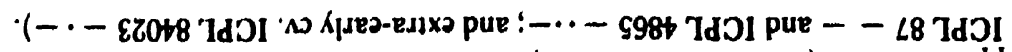

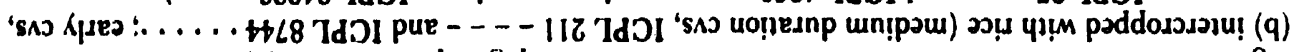

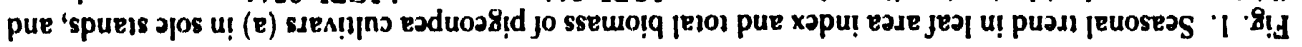

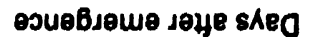

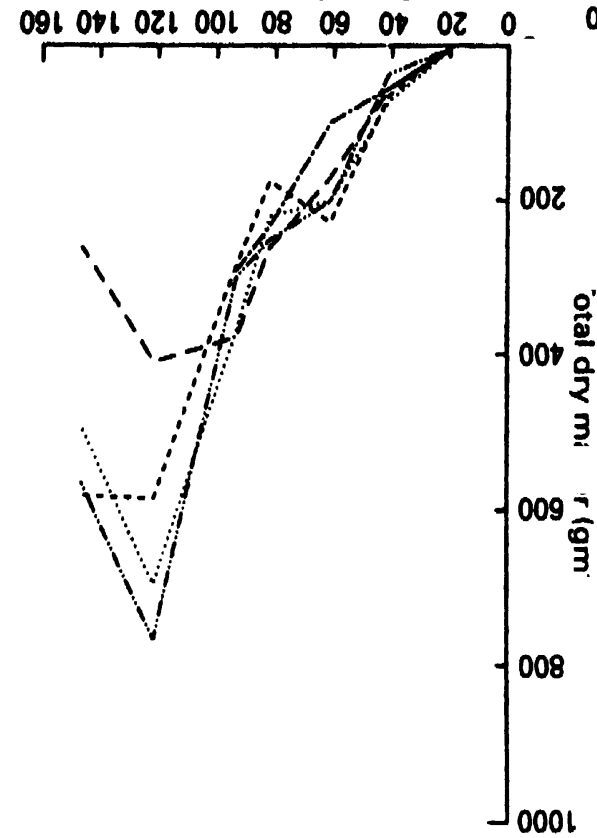

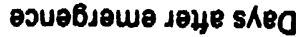

$0910 t 102100108 \quad 09$ ot 02
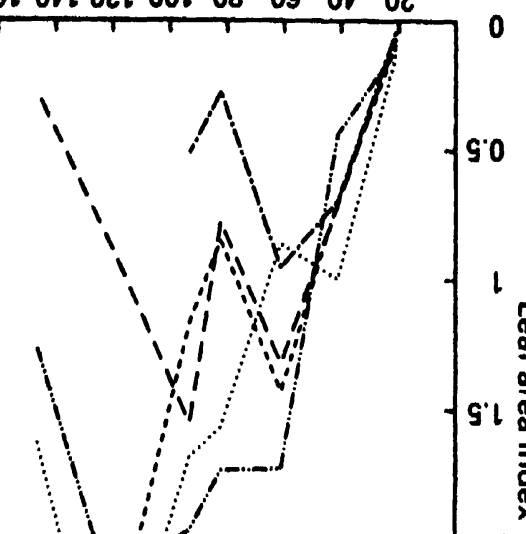

1

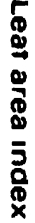

$\tau$

(q)

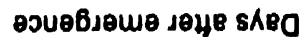

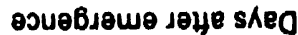

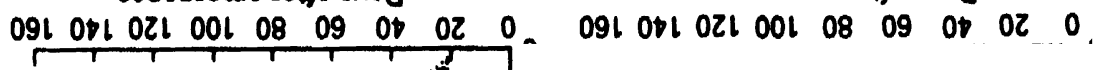

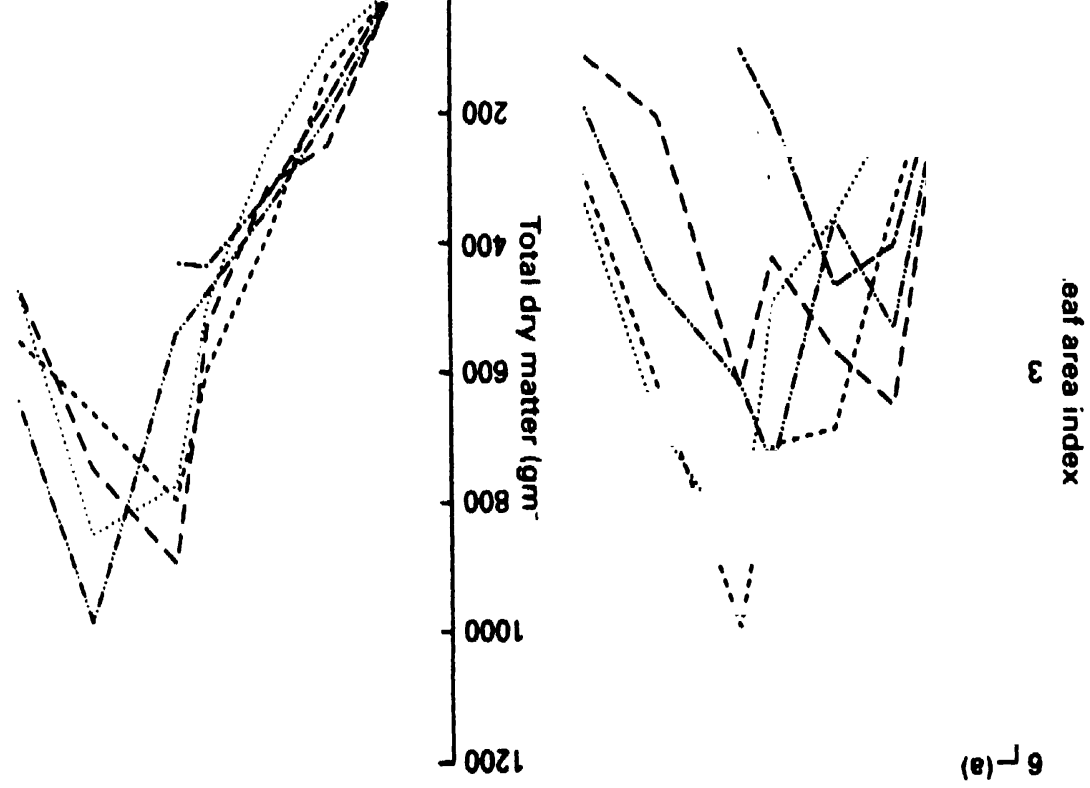




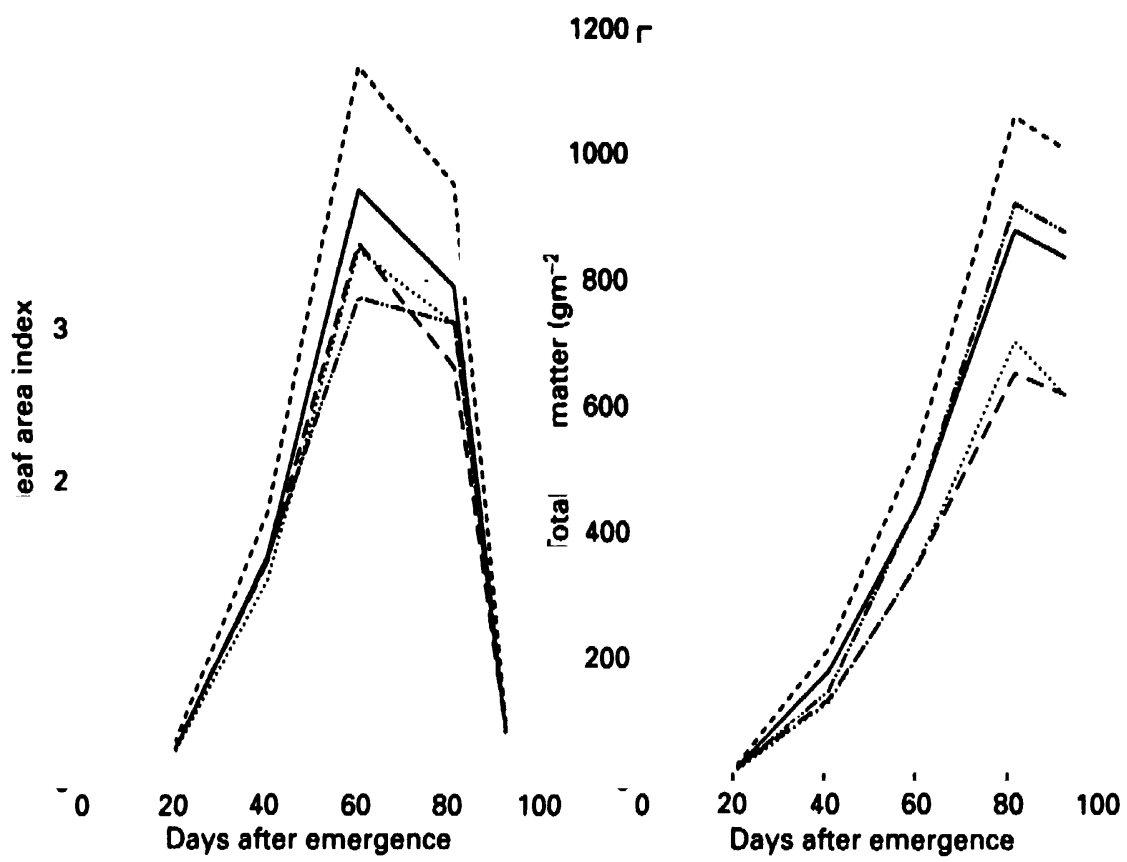

Fig. 2. Scasonal trend in leaf area index and total biomass of sole rice (- - ) and of rice intercropped with medium duration $(\cdots \cdots)$, early $(--)$ and extra-early $(-\cdots-)$ pigeonpea cultivars. Expected values for intercropped rice (calculated on the hasis of sole rice stands of the same area) are provided for comparison (-).

had the fastest rate of canopy development from 20 to 40 days after sowing. Surprisingly, the erect branching ICPL 211 had the largest maximum leaf area index ( $L$ ) and a considerably faster rate of canopy formation than ICPI. 8744; the trend in the initial growth rate of the canopy was reflected in the trend in dry matter production (Fig. la).

The trend in L of the intercropped pigeonpea (Fig. Ib) is not clear because of mortality and leaf fall caused by excess soil moisture resulting from continuous heavy rains at 80 days after emergency (DAE). This effect of excess soil moisture on yield reduction was also apparent in the accumulation of dry matter over the same period. Surprisingly, this check on growth was not detected in sole pigeonpea stands. Since one of the extra-early cultivars, ICPL 83015, suffered $95 \%$ mortality because of its susceptibility to excess soil moisture in both sole and intercropping systems, its contribution could not be assessed.

In sharp contrast to pigeonpea, the development of leaf area in intercropped rice was limited in all the intercropping systems (Fig. 2). The $L$ of intercropped rice was unaffected when compared to the 'expected' value, except for the period 60 to $90 \mathrm{DAE}$, when $\mathrm{L}$ was already close to 3.0 or more. The pattern of dry matter production was quite different from that of $\mathrm{L}$, with only the extra-early pigeonpea combination giving values larger than the expected value (Fig. 2).

Reasons for the differences in the pattern of $\mathrm{L}$ and dry matter production in intercropped rice become obvious when the relative height of the pigeonpea and 
Table 2. Pigeonpea plant height and height above rise (om) at rice hanest

\begin{tabular}{|c|c|c|}
\hline Treatment & Piyeonpea & $\begin{array}{l}\text { Relative height of } \\
\text { pigeonpea and rice }\end{array}$ \\
\hline \multicolumn{3}{|l|}{ Sole pigeonpea } \\
\hline \multicolumn{3}{|c|}{ Medium duration cvs } \\
\hline IC.PL. 211 & 147 & 6.5 \\
\hline ICPL 8744 & $1+7$ & (6) \\
\hline \multicolumn{3}{|l|}{ Early cvs } \\
\hline IC.PL 87 & 117 & 36 \\
\hline IC:PL 4865 & 171 & $9)$ \\
\hline \multicolumn{3}{|l|}{ Extra-early cs: } \\
\hline IC:PI. $8+023$ & 89 & 8 \\
\hline \multicolumn{3}{|l|}{ Rice/pigeonpea } \\
\hline \multicolumn{3}{|c|}{ Medium duration cvs } \\
\hline IC.PL 211 & 139 & 59 \\
\hline IC:PI, 8744 & 160 & 79 \\
\hline \multicolumn{3}{|l|}{ Early cvs. } \\
\hline IC:PL. 87 & 110 & 32 \\
\hline ICPI, 4865 & $1+2$ & 57 \\
\hline \multicolumn{3}{|l|}{ Exira-early cv. } \\
\hline IC:PL, 84023 & 84 & 1 \\
\hline
\end{tabular}

rice canopies are compared (Table 2). With the extra-carly pigeonpea there was virtually no difference in the height of the two canopies, whereas in all the other combinations the rice canopy was shaded by the bulk of the pigeonpea leaves. Indeterminate branching types such as ICPL 4865, 211 and 8744 were substantially taller than upland rice.

\section{Light interception}

Fractional light interception (f) by the pigeonpea genotypes and rice is shown in Fig. 3a. Both rice and pigeonpea had markedly different rates of change of $f$ with time $\left(R_{f}\right)$ and there were large differences between pigeonpea genotypes. Pigeonpea $\mathrm{cv}$. ICPL 4865 and ICPL 87 produced the highest $R_{f}$ recorded and reached a maximum $f$ which exceeded the rice value by $15-20 \%$. The $R_{f}$ of ICPL 211 and 8744 was intermediate between ICPL 4865 and 87 , reaching a maximum fof 0.8 . The decline in $\mathrm{f}$ was earliest and most pronounced in 84023 due to leaf fall after 60 DAE. ICPL 87 , followed by 4865 , also showed a $10-15 \%$ decline in $f$ from $120 \mathrm{DAE}$ onwards, reflecting the determinate nature of these cultivars, compared with the indeterminate cultivars ICPL 211 and 8744 in which $f$ gradually decreased from 140-200 DAE.

Intercropping consistently increased the value of $R_{f}$ above that of sole rice treatments but the maximum value of $f$ was relatively unaffected by intercropping (Fig. 3b). Pigeonpea cultivars ICPL 84023 and ICPL 87 in the intercropped system showed a steep decline in $\mathrm{f}$ when the rice was harvested but there was no comparable decline in the ICPL 211,8744 and 4865 intercrops because of compensatory growth by these genotypes. 


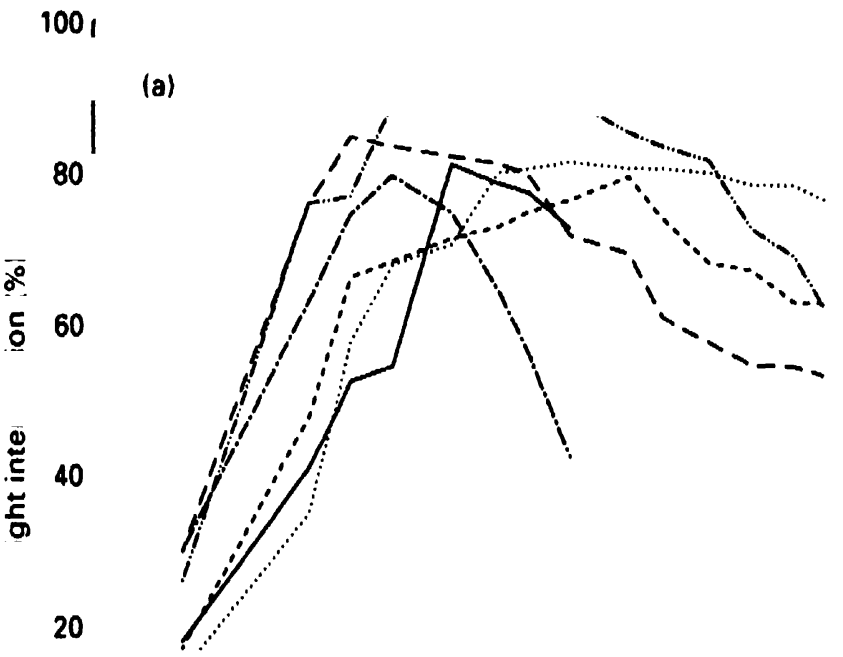

50

100

150

200

Days after emergence

100

(b)

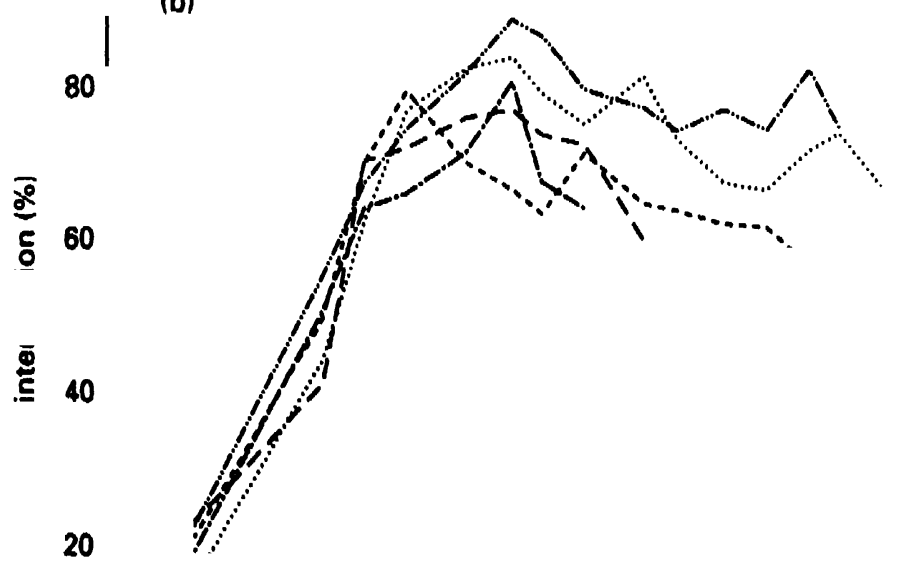

0

50

Fig. 3. Seasonal light interception by rice $(-)$ and pigeonpea cultivars (a) in sole stands and (b) when intercropped (pigeonpea cultivars as in Fig. 1). 
Table 3. Accumulaced intercepted radiation (IR) and light use efficiency (e) of sole and intercrops - from 20 to 100 dạys after souving (expecited calues in paremtheses)

\begin{tabular}{|c|c|c|c|}
\hline Treatment & $\operatorname{IR}\left(\mathbf{M} \mathrm{J} \mathrm{m}^{-2}\right)$ & $c\left(g . M J^{-1}\right)$ & $\boldsymbol{k}$ \\
\hline Rice sole & 771 & 1.30 & (1). 36 \\
\hline \multicolumn{4}{|l|}{ Pigeonpea sole } \\
\hline \multicolumn{4}{|c|}{ Medium duration cvs } \\
\hline IC.PI. 211 & 817 & 0.97 & 0.45 \\
\hline IC.PL 8744 & 776 & 0.99 & 0.60 \\
\hline \multicolumn{4}{|l|}{ Early cr's } \\
\hline IC.PI. 87 & 1025 & 0.87 & 0.54 \\
\hline IC:PI, 486.5 & 1065 & 0.51 & 0.78 \\
\hline \multicolumn{4}{|l|}{ Fxtra-early cr. } \\
\hline IC:PI, 84023 & 864 & 0.50 & 01.64 \\
\hline \multicolumn{4}{|c|}{ Rice/pigeonpea intercrop } \\
\hline \multicolumn{4}{|c|}{ Medium duration cvs } \\
\hline IC.PI. 211 & $828(1048)$ & $1.20(1.56)$ & \\
\hline ICPI. 87+4 & $845(1028)$ & $1.05(1.57)$ & \\
\hline \multicolumn{4}{|l|}{ Early cos } \\
\hline IC.PL 87 & $835(896)$ & $1.29(1.29)$ & \\
\hline IC:PL, 4865 & $924(906)$ & $0.91(1.20)$ & \\
\hline $\begin{array}{l}\text { Extra-early c1. } \\
\text { ICPI. 840'23 }\end{array}$ & $812(8.56)$ & $1.38(1.20)$ & \\
\hline
\end{tabular}

The consequence of intercropping on light interception was analysed in terms of the amount of radiation intercepted (IR) and the light use efficiency (e) during the period from 30 to 100 DAE (Table 3). In general the total amount of IR was not increased by intercropping when compared with 'expected' values, except in the case of ICPL 4865 where there was a marginal increase of $2 \%$. This can be attributed to mortality and/or reduced growth and leaf expansion in the pigeonpea as a result of excess moisture. The light use efficiency of the intercrops was reduced by $22-33 \%$ of the 'expected' values except for the extra-early pigeonpea ICPL 84023/rice system. This is not surprising since a larger proportion of the radiation was intercepted by the legumes. The greatest reduction was recorded with the ICPL 8744/rice system. In general the value of e for rice was 1.5 to 2.5 times greater than for legumes.

\section{Transmission coefficient $(K)$}

The transmission coefficient $(K)$ was calculated from the Beer-Lambert law at the time of the rice harvest for both rice and pigeonpea (Table 3 ). $K$ values differed between the pigeonpea genotypes. The K of ICPL 4865 was about 0.78 , the largest value of all the pigeonpea genotypes, implying a more horizontal canopy structure and more light interception per unit leaf area. In contrast, the value of $K$ for ICPL 211 of 0.45 was outside the general range of $0.6-0.7$ for other pigeonpea genotypes, but is characteristic of an erect canopy structure. The value of $\mathrm{K}$ for upland rice was 0.36 , typical of a cereal with a very erect canopy. 
Table 4. Partial and total land equivalent ratios (LER) and crop performance ratios (CPR) of ricel pigeonpea intercrops

\begin{tabular}{|c|c|c|c|c|c|c|c|c|c|}
\hline & & & & \multicolumn{6}{|c|}{ CPR } \\
\hline & \multicolumn{3}{|c|}{ I.ER (grain) } & \multicolumn{3}{|c|}{ Grain } & \multicolumn{3}{|c|}{ Total biomass } \\
\hline & Rice & Ppea & Total & Rice & Ppea & Total & Rice & Ppea & Total \\
\hline \multicolumn{10}{|c|}{ Rice with pigeonpea } \\
\hline \multicolumn{10}{|c|}{ Medium duration cos } \\
\hline IPIC: 211 & 0.84 & 0.60 & 1.44 & 1.01 & 1.19 & 1.0 .5 & 0.93 & 1.16 & 1.01 \\
\hline IC:PI. 8744 & 0.54 & 0.62 & 1.16 & 0.6 .5 & 1.23 & 0.74 & 0.7 .5 & 1.97 & 1.10 \\
\hline \multicolumn{10}{|l|}{ Farly cos } \\
\hline IC:PI. 87 & 0.83 & 0.49 & 1.32 & 1.00 & 1.98 & 1.14 & 0.86 & 1.65 & 1.01 \\
\hline IC:PL 4865.5 & 0.58 & 0.70 & 1.28 & 0.69 & 2.80 & 0.89 & 0.75 & 2.4 .5 & 1.10 \\
\hline \multicolumn{10}{|l|}{ Extra-carly rv. } \\
\hline I('PI, 840)'3 & 0.94 & 0.72 & 1.66 & 1.13 & 2.89 & 1.27 & 1.04 & 1.93 & 1.19 \\
\hline
\end{tabular}

\section{Land equivalent ratios (LERs)}

When intercropped with pigeonpea cultivars ICPL 211, 87 and 84023, rice produced LERs similar or more than the 'expected' LER of 0.83 (Table 4). Intercropping with the extra-early pigeonpea cultivar, ICPL 84023, produced the largest total LER (1.66). Both early maturing pigeonpea cultivars gave similar total I.ERs, but ICPL 87 had a negligible effect on rice yield whereas ICPL 4865 reduced the partial LER of rice from an 'expected' 0.83 to 0.58 .

However, intercropped IC.PI, 87 was less able to compensate for the low population than intercropped ICPI. 4865. Similarly, the medium duration pigeonpea ICPI. 211 had virtually no effect on the yield of intercropped rice compared with ICPL 8744 (partial L.ER $=0.54$ ). Thus the high total I.ER of 1.44 for ICPL 211 intercropped with rice is not strictly related to the duration or phenology of the pigeonpea cultivars, although the extra-early genotype (ICPL 84023) gave the highest total LER.

\section{Crop performance ratios (CPRs)}

To examine the relative performance of each plant in sole crops and intercrops, the crop performance ratios (CPR) of rice and pigeonpea for grain and total biomass and the values for the combined intercrop system were calculated (Table 4). All the pigeonpea genotypes performed better in the intercrops, with CPRs ranging from 1.16 to 2.89 in terms of biomass and grain yield. The largest partial CPR for grain was recorded for the extra-early genotype, followed by early and medium genotypes, while the largest partial CPR for total biomass was recorded for the early genotypes, followed by medium and extra-early genotypes. Spreading genotypes have larger partial CPRs than semi-compact genotypes.

CPRs for intercropped rice calculated for grain were greater than unity for ICPL 211,87 and 84023 but only intercropped ICPL 84023 and rice had a total biomass CPR exceeding unity. In contrast, the CPR of intercropped rice with the 
spreading type of pigeonpeas (IC.PL 8744 or IC.PI. 486.5 ) was between 0.65 and 0.69 for grain.

In general TC.PR values were smaller than TL.ER values (Table 4). For example the TLER of pigeonpea cr. IC.PL.8744/rice system was 1.16 , whereas the TC.PR was less than unity. Similarly, the IC.PI. 486.5/rice system had no biological advantage in terms of TC.PR, but appeared to have a $28 \%$ yield advantage in terms of TLER. The most appropriate pigeonpea genotype for intercropping in terms of both the TIER and TC.PR was IC.PI. 84023.

\section{DISC:ISSION}

The present study confirmed our earlier observation (Ramakrishna and Ong, 1991) that, provided a suitable pigeonpea cultivar is used, a considerable intercropping advantage can be achieved in a pigeonpea/upland rice intercropping system without a substantial reduction in intercropped rice yield. In our previous study only one early and one medium maturity cultivar were used so it was impossible to assess the importance of phenology on the competition between component species. The present study showed that the phenology of pigeonpea is relatively unimportant compared with canopy structure and relative plant height. For example, the medium duration and erect canopy type, IC:PI, 211, gave a larger I.ER (1.44) than the early duration IC:PI 87 (1.28), which was also used in the previous study (Ramakrishna and Ong, 1991), but neither competed significantly with intercropped rice. On the other hand, the horizontal canopy types, ICPL 8744 (medium) and ICPL 486.5 (early), severely reduced intercropped rice yield.

Unfortunately, only one of the extra-early types, IC.PI, 84023, survived the effect of excess soil moisture to allow comparison with the other genotypes. The limited information on the canopy structure of extra-early types suggests that IC.PL 84023 has $\mathrm{K}$ values between 0.6 and 0.7 , typical of high yielding extra-early cultivars (Nam, 1989), and that their plant height in the Deccan plateau of India is between 0.8 and $1.2 \mathrm{~m}$ during the rainy season. Under such conditions, the canopy structure of the extra-early cultivars is unlikely to compete severely with intercropped rice because for much of the growing period the two canopies are about the same height. The LER of intercropped rice would therefore be similar to the value reported here and total LER would be expected to remain high. However, if excess rain greatly reduces pigeonpea growth then the extra-early cultivars may not have the capacity to compensate after the harvest of the rice. In addition, research at ICRISAT suggests that the present range of extra-early cultivars is more prone to excess soil moisture than the medium duration types.

Amongst the longer duration pigeonpea cultivars used in this study, there appears to be a large enough variation in $\mathrm{K}$ to provide a selection for canopy structure suitable for intercropping with upland rice. The $K$ value of the early type, ICPL 87 (0.54), was intermediate between the values of ICPL 211 and ICPL 4865. With early and extra-early cultivars there may not be much 
advantage to selection for more erect canopy type since the yield of intercropped rice is virtually unaffected and capacity to compensate for the reduced population of intercropped pigeonpea is limited. In fact the LER for ICPL 87 in the present study was considerably less than in the previous study, when it was 1.45-1.56 (Ramakrishna and Ong, 1991), suggesting that it was even less able to compensate than the extra-early cultivar ICPL $84023(\mathrm{~K}=0.64)$. It may also be argued that a further improvement in the canopy structure of medium duration types, like ICPL 211 , that give $\mathrm{K}$ values below 0.45 may not have the advantage of reducing competition in intercropped rice.

Another factor which appears to determine the competitive capacity of intercropped species is relative plant height (Table 2). Earlier we suggested that the height of ICPL 84023 is typical of the extra-early types in the Deccan plateau. Unpublished results (S. C. Gupta, personal communication) of multi-locational trials in coastal and inland Andhra Pradesh reveal considerable variation in height of both extra-early and early types, depending on levels of light and the saturation deficit. Thus it would be unsafe to extrapolate from our experience in the drier and brighter locations to the contrasting conditions of areas where upland rice is more commonly grown with pigeonpea. Further research on pigeonpea/upland rice is therefore needed to determine the sensitivity of plant height in pigeonpea to environmental factors. Upland rice is also very sensitive to weak light, particularly during the reproductive phase when it can cause spikelet abortion (Dash and Rao, 1990).

Acknowledgements. We wish to thank $\mathrm{Mr} \mathrm{A}$. A. H. Khan for assistance in measuring light interception and Mr K. V. Ravindra for computer services. In the course of study a number of technicians-Mr P. Keshava Reddy, Mr K. Ashok Reddy, Mr B. S. R. Murthy, Mr K. Muir, Mr Bikshapathi and Mr A. V. Rao-assisted us in the field work. Thanks are also due to Mr K. N. V. Satyanarayana, Mr K. P. Ch. Raju and Mr V. Mohan Reddy for secretarial assistance.

\section{REFERENCES}

Dash, C. R. \& Rao, Ch. N. (1990). Effect of varying light intensities on yield and yield components of rice plant types. Oryza 27:90-93.

Freyman, S. \& Venkateshwarlu, J. (1977). Intercropping on rainfed red soils of the Deccan Plateau, India. Canadian Joumal of Plant Science 57:697-705.

Harris, D., Natarajan, M. \& Willey, R. W. (1987). Physiological basis for yield advantage in a sorghum/ groundnut intercrop exposed to drought. 1. Dry matter production, yield and light interception. Field Crops Research 17:259-272.

Jena, D. \& Misra, C. (1988). Effect of crop geometry (row proportions) on the water balance of the root zone of a pigeonpea and rice intercropping system. Experimental Agriculture 24:385-391.

Matthews, R. B., Saffell, R. A. \& Campbell, G. S. (1987). An instrument to measure light distribution in row crops. Agricultural and Forest Meteorology 39:177-184.

Nam, H. N. (1989). Comparison of extra-short-duration pigeonpea genotypes with traditional shortseason legume varieties for contingency cropping in droughted environments. MSc thesis submitted to Andhra Pradesh Agricultural University, Rajendranagar, Hyderabad, India. 
Vatarajan, M. \& Willey, R. W. (1979). Growth studies in sorghum/pigeonpea intercropping with particular emphasis on canopy development and light interception. In Procedings of the Intermational IVorkshop on, Intercropping, 10-13 January 1979, 180-187. Hyderabad, India: International Crops Research Institute for the Semi-Arid Tropics.

Parida, D., Dikshit, U. N., Satpathy, D. \& Mahapatra, P. K. (1988). Pigeonpen genotypes and rice yield in an intercropping system. International Rice Research Neuisletter 13:26-27.

Ramakrishna, A. \& Ong. C. K. (1991). Productivity and light interception in upland rice/legume intercropping systems. Tropical Agriculture (in press).

Rao, M. R. \& Willey, R. W. (1980). Prelininary studies of intercropping conibinations based on pigeonpea or sorghum. Experimental Agriculture 16:29-39.

Rao, M. R. \& Willey. R. W. (1983). Effects of genotype in cereal/pigeonpea intercropping on the Alfisols of the semi-arid tropics of India. Experimental Agriculture 19:67-78.

Singh, P. \& Virmani, S. M. (1990). Evapotranspiration and yield of irrigated chickpea. Agriculture and Forest .Meteorologv 52:333-345. 